\title{
Fusions between Successive Deposition Droplets Impinging on a Moving Substrate Surface
}

\author{
Suli Li ${ }^{1,2, a}$, Laixia Yang ${ }^{1, b, *}$, Yang Gao ${ }^{1, c}$, Chao Xu ${ }^{1, d}$, Bingheng Lu ${ }^{2, e}$ \\ ${ }^{1}$ School of Xi'an University of Science and Technology, Xi'an 710054, China \\ 'School of Xi'an Jiaotong University, Xi'an 710049, China. \\ a563456137@qq.com, blaixiayang@yahoo.com, c57070374@qq.com, d9525512@qq.com, \\ ebhlu@xjtu.edu.cn
}

Corresponding author: Laixia Yang

Keywords: Molten metal droplets, Successive deposition, Heat transfer, VOF, Fusion.

\begin{abstract}
Successive deposition of uniform metal droplet is a new kind of 3D printing and rapid prototyping (RP) technology. Broad interests have been aroused in the deposition of metal droplets due to its potential application in microstructures fabrication. In this paper, the $3 \mathrm{D}$ models based on a volume of fluid (VOF) method were developed to investigate the successive deposition of molten metal droplets on a horizontally moving aluminum substrate surface and manufactured the typical thin-walled parts using the process of metal droplet deposition. The impinging, spreading and fusion processes of droplets were investigated under uniform substrate velocities. The simulated final morphology of droplets agreed well with experiments carried out under the same conditions. It was found that the molten metal droplets solidified in a layer by layer from the outer to the inner due to the high heat conductivity. A series of arc-shaped ridges appeared on the surface of solidified droplets, which resulted from the integrated effects from solidification and fusion consisting of alternately spreading and fusion of droplets. The works should be helpful for the process optimization and non-destructive detection of drop-based rapid prototyping techniques.
\end{abstract}

\section{Introduction}

The 3D printing and rapid prototyping (RP) technology are applied more and more widely, including metal deposition manufacturing technology under different parameters of impinging, spreading and fusion which have get a wide application in modern industry [1]. The 3D printing and rapid prototyping (RP) technology by successive deposition metal droplets are an additive process, and the components are manufactured from molten metal materials in a single operation without the use of a mold or other tooling. Near net shape parts are fabricated by sequentially depositing molten droplets layer by layer [2]. Up to now, the generation of molten metal droplets has been developed into two main modes: continuous jetting [3-8] and drop-on-demand (DOD) jetting [9, 10]. The former mode can produce high frequency droplets with a piezoelectric ceramic actuator. However, it is difficult to control the fall position and temperature of the droplets compared to the second one. The second one has excellent controllability in the velocity, temperature and diameter of the droplets, resulting in the extensive applications from the printing of electronic circuits to the fabrication of 3D components [11]. In the DOD mode, the molten metal in the crucible for jetting can be ejected out from a nozzle by heat, charge or gas pulse. Among these, gas pulse is readily to generate metal droplets.

Currently, the simulation works related to droplet deposition and fusion processes are mainly based on 2D models, which focus on the normal impinging of single droplet onto a fixed substrate surface [12-21]. However, 2D models could not provide comprehensive details of the deposition process. Thus, a 3D model has been developed to study complex flows in the successive deposition process of droplets [22-25]. Ghafouri-Azar et al. [26] investigated the inter-impinging of two tin droplets with the diameter of millimeter scale, and simulated the fusion behaviors of droplets. Furthermore, there are few reports on the successive droplets impinging on a substrate surface. Xu et al. [27] investigated the 
fusion process of droplets by assuming that the impinging droplets were pre-deformed into cylindrical discs with a given thickness. The droplet morphology was considered as a disc after impacting with a substrate and the fluid dynamics of spreading and fusion of droplets were neglected.

During the fabrication process of 3D components by DOD technique, droplets are deposited onto a horizontally moving aluminum substrate surface and fusion each other to form a line and layer. However, successive deposition and solidification of molten metal droplets on the horizontally moving substrate have not been studied. In this paper, the successive deposition and solidification of molten aluminum droplets on a horizontally moving aluminum substrate were numerically simulated by a 3D model based on the volume of fluid (VOF) method. In order to confirm the implications of the numerical simulations, molten metal droplets were successively generated by the DOD jetting and deposited onto a horizontally moving substrate surface. The 3D images of morphology evolution of droplets were also discussed.

\section{Modeling and analysis}

The present study aims at developing a model of successive deposition of uniform molten metal droplets on a horizontally moving substrate. So, the model consists of droplets (the first droplet, the second droplet, the third droplet and the fourth droplet), a substrate and air, as shown in Fig.2. Several assumptions have been made as follows:

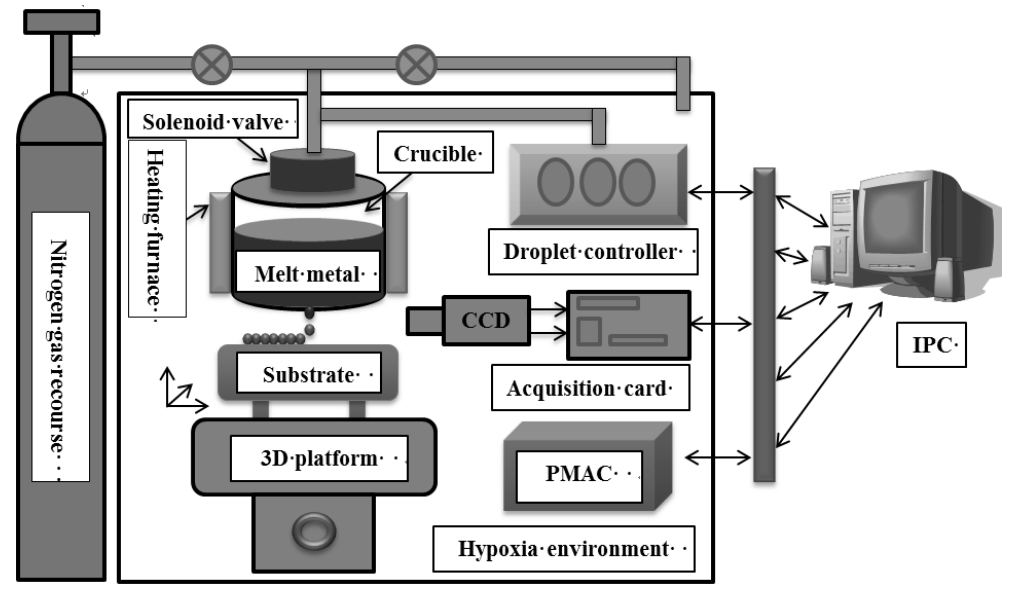

Figure 1. Schematic diagram

(1) The droplets with spherical morphology are generated at a fixed velocity $\mathrm{V}$.

(2) The initial temperature distribution within droplets is uniform.

(3) The substrate is horizontally moved at a constant velocity VS.

(4) The surrounding gas is considered as a void region, and thus the heat loss of droplets by convection and radiation are ignored.

The initial conditions of the model are shown in Table 2. All domains above the substrate are initialized with a void except the droplet. Both the velocity and pressure of the void region are zero. The velocities of droplets generated by the DOD jetting are generally slow, and true velocities are difficult to be measured or estimated. The initial velocities at every point inside droplets are assumed to be $1 \mathrm{~m} / \mathrm{s}$ according to the results of Fang et al. [39]. The initial diameters of droplets are determined by measuring fully solidified droplets collected in DOD jetting experiments. The boundary conditions of the computational domain are set as "continuative", which represents a smooth continuation of the flow through the boundary.

This article carries out process parameters of deposition experiments, as is shown in table 1 . 


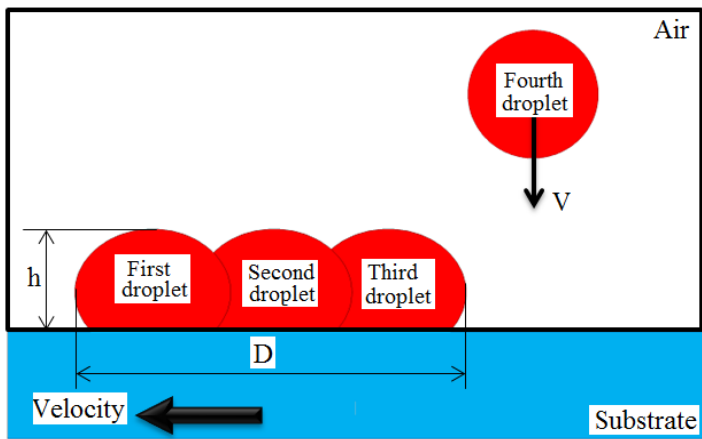

Figure 2. Schematic representation of the mathematical model for successive droplets deposition

Table1. Process parameters of deposition experiments

\begin{tabular}{|c|c|}
\hline Parameter & Value \\
\hline Droplet material & Aluminum \\
\hline Droplet density $\left(\rho / \mathrm{kg}^{\left.-\mathrm{m}^{-3}\right)}\right.$ & 2368 \\
\hline Droplet surface tension $\left(\sigma / \mathrm{N}^{\circ} \mathrm{m}^{-1}\right)$ & 0.8 \\
\hline Droplet melting point $\left(\mathrm{T} /{ }^{\circ} \mathrm{C}\right)$ & 933 \\
\hline Droplet velocity $\left(\mathrm{V} / \mathrm{m}^{-1} \mathrm{~s}^{-}\right)$ & 1 \\
\hline Droplet temperature $\left(\mathrm{T}_{\mathrm{d}} / \mathrm{K}\right)$ & 935 \\
\hline Substrate temperature $\left(\mathrm{T}_{\mathrm{S}} / \mathrm{K}\right)$ & 300 \\
\hline Droplet diameter $(\mathrm{d} / \mathrm{mm})$ & 0.2 \\
\hline Inlet pressure $(\mathrm{Ps} / \mathrm{MPa})$ & 0.2 \\
\hline Deposition distance $(\mathrm{Hs} / \mathrm{mm})$ & 10 \\
\hline Solidification angle $\left(\theta /{ }^{\circ}\right)$ & 90 \\
\hline Substrate material & Aluminum \\
\hline Substrate density $(\rho / \mathrm{kg} \cdot \mathrm{m}-3)$ & 2700 \\
\hline Substrate heat capacity $(\mathrm{CP} / \mathrm{j} \cdot \mathrm{kg}-1 . \mathrm{k}-1)$ & 900 \\
\hline Substrate diffusivity $(\alpha / \mathrm{m} 2 \mathrm{~s}-1)$ & $9.75 \mathrm{e}-5$ \\
\hline Substrate thermal conductivity $(\mathrm{k} / \mathrm{w} \cdot \mathrm{m}-1 . \mathrm{k}-1)$ & 237 \\
\hline
\end{tabular}

\section{Results and discussion}

\subsection{Deposition of the droplets}

\subsubsection{Deposition of the first droplet}

Fig. 3 shows the morphology evolution of a single droplet during dripping and spreading onto a moving substrate. It is observed that the droplet has been stuck to the substrate and dragged forward after $4 \mu \mathrm{s}$. Calculation results also show that the droplet spreads without rolling during deposition, which is the same with experimental result [24]. In this simulation, once the droplet contacts the cold substrate, it is simultaneously cooled by means of heat transfer to the substrate and begins to solidify.

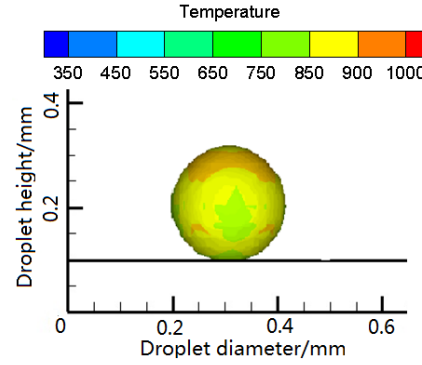

(a) $1 \mu \mathrm{s}$

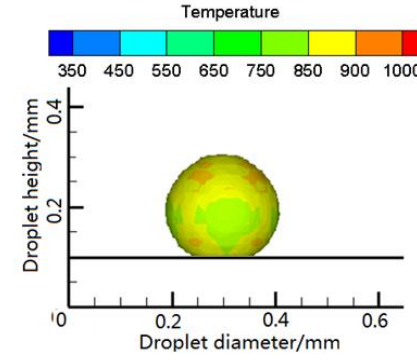

(b) $4 \mu \mathrm{s}$
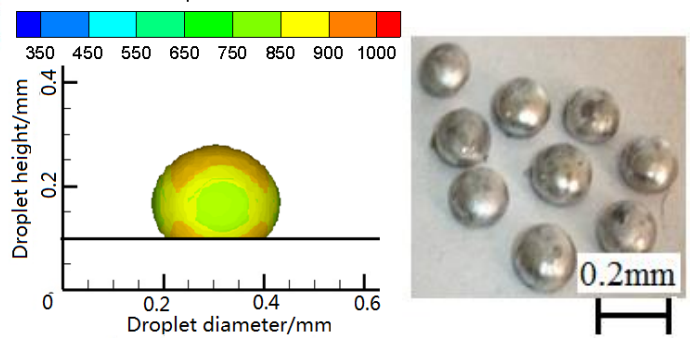

(c) $8 \mu \mathrm{s}$

Figure 3. Calculated 3D images of morphology evolution of the first droplet 
3.1.2. Deposition of the second droplet

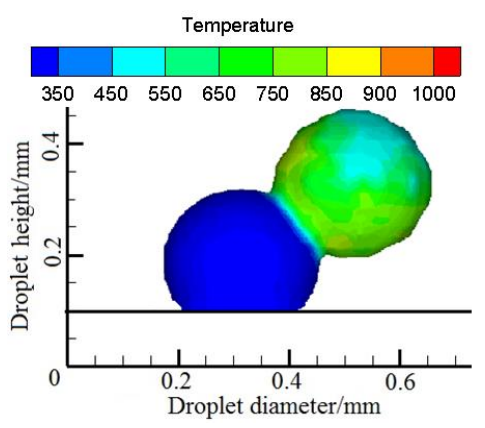

(a) $12 \mu$

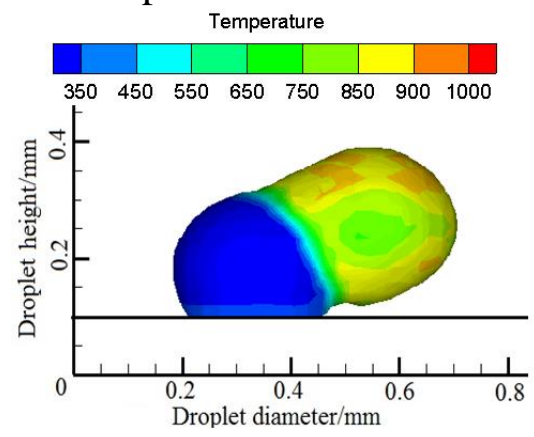

(b) $14 \mu \mathrm{s}$

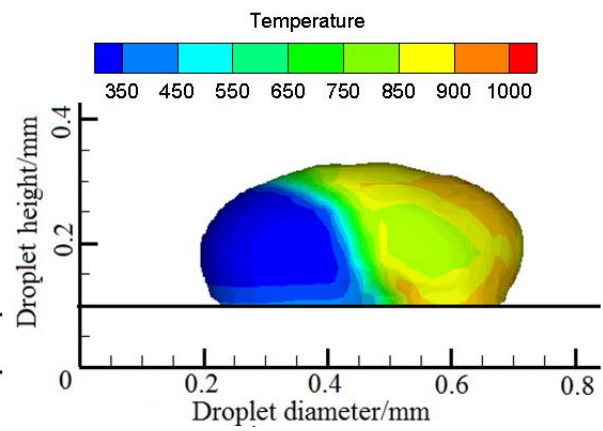

(c) $28 \mu \mathrm{s}$

Figure 4. Calculated 3D images of morphology evolution of the second droplet

Fig.4 shows the morphology evolution of fusion between the first droplet and the second droplet. At the substrate velocity of $1.4 \mathrm{~mm} / \mathrm{s}$, the second one initially impinges the top right surface of the first droplet. Meanwhile, the solidification form outer to inner of the second droplet and the first droplet, which would result in some frozen layer at the contact area. As can be verified by the appearance of the interface between the two droplets, this frozen layer is prejudice for metallurgical bonding between these two droplets. But as the fusion between molten droplets, the interface between the two droplets will gradually decrease. Due to lack of enough support from the partially remelted droplet, the second droplet comes into contact with the substrate, increasing the area of heat dissipation for the second droplet. Thus, the heat carried by the second droplet transfers to the conjoint droplet, which is confirmed by the solidification of the second droplet.

3.1.3. Deposition of the third droplet
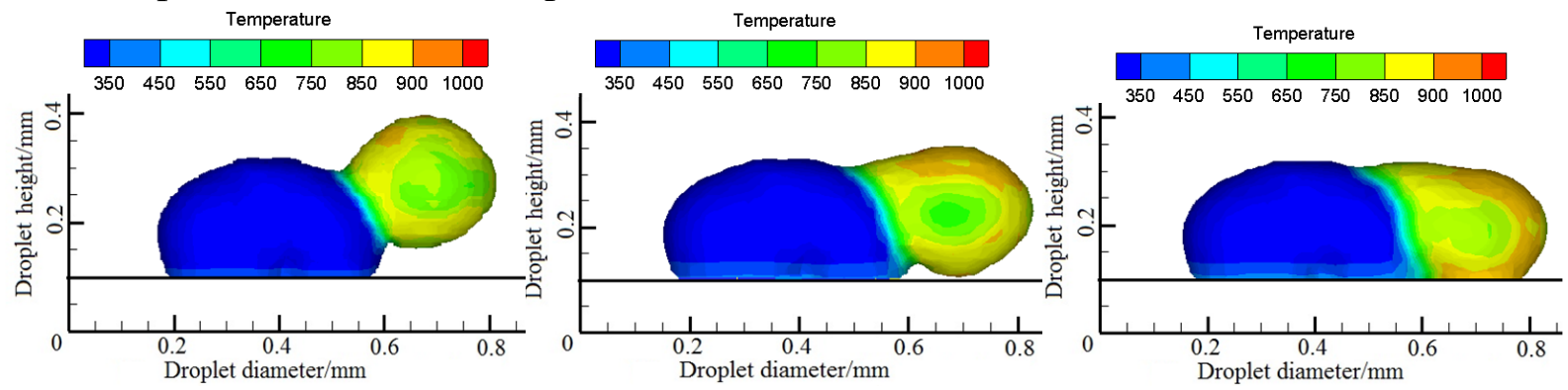

Figure 5. Calculated 3D images of morphology evolution of the third droplet

The third droplet closely resembles the second one in both phase field and morphology evolution, as shown in Fig5. However, the interface between the second droplet and the third droplet slightly increases when comparing Fig.5 with Fig.4. This delay in solidification may contribute to maintain fluidity. In this droplet deposition regime, the solidification of the melt takes place faster than the melt spreading, leading to the non-filling of the melt into the pore under the droplet splat [20]. This problem may be partially solved by increasing the temperature of $\mathrm{Al}$ melt and the substrate.

3.1.4. Deposition of the fourth droplet
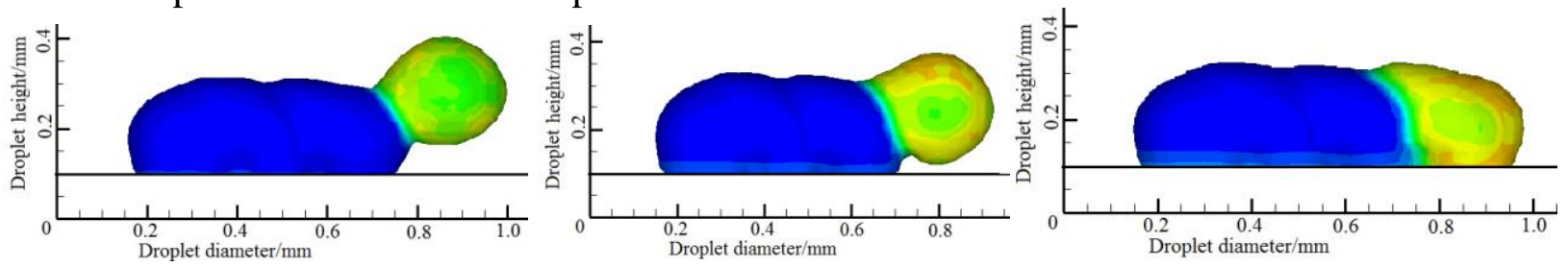

Figure 6. Calculated 3D images of morphology evolution of the fourth droplet

The fourth droplet closely resembles the second one and the third one in both phase field and morphology evolution, as shown in Figs.6. However, the interface between the third droplet and the fourth droplet slightly increases when comparing Fig.6 with Fig.5. This delay in solidification may 
contribute to maintain fluidity and decrease the pore. But the pore is difficult to completely eliminate. In this droplet deposition regime, the solidification of the melt takes place faster than the melt spreading, leading to the non-filling of the melt into the pore under the droplet splat. This problem may be partially solved by increasing the temperature of $\mathrm{Al}$ melt and the substrate.

\subsection{The fusions between molten metal droplets}

Figure 7 shows the time evolution of the change of droplets spreading diameter and height. As can be seen that it is divided into four areas respectively: (1) the first metal molten droplet is dripping and spreading; (2) the second metal molten droplet is dripping and fusing with the first droplets; (3) the third metal molten droplet is dripping and fusing with the second droplets; (4) the fourth metal molten droplet is dripping and fusing with the third droplets.

Before $4 \mu \mathrm{s}$, the first droplet was dripping at a constant speed, and the spreading height $\mathrm{h}$ declined with linear, because the droplet was no contacting with the substrate, the spreading diameter D has been unchanged; After $4 \mu \mathrm{s}$, the first droplet began to contact with the substrate and spread out, the spreading diameter $\mathrm{D}$ showed a trend of increasing, due to the resistance of the substrate, the increasing velocity of spreading height $\mathrm{h}$ reduced; The spreading diameter $\mathrm{D}$ and spreading height $\mathrm{h}$ of the first droplet are all unchanged after $15 \mu \mathrm{s}$; this is shown that the droplet has been completely frozen. At this time, the spreading height $\mathrm{h}$ is $0.18 \mathrm{~mm}$, and spreading diameter $\mathrm{D}$ is $0.255 \mathrm{~mm}$.

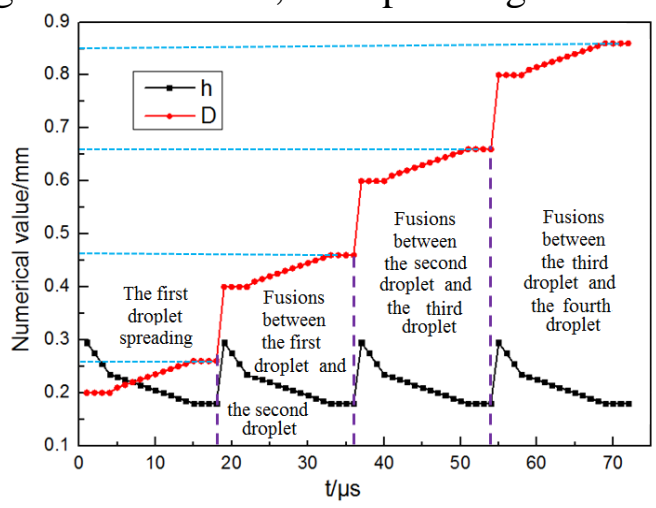

Figure 7. Time evolution of the droplets height $h$ and the diameter $\mathrm{D}$

From the point of spreading diameter $\mathrm{D}$, it increases a certain value when spreading out a single droplet. The value basic equals to the droplet diameter, this is associated with the moving velocity of substrate.

\subsection{Model validation}

In order to validate our model and simulation, experiments were done with molten Al droplets having diameter of $1.5 \mathrm{~mm}$ and initial temperature of $1073 \mathrm{~K}$. The droplets were generated at a rate of $1 \mathrm{~Hz}$ and successively deposited onto a horizontally moving substrate.

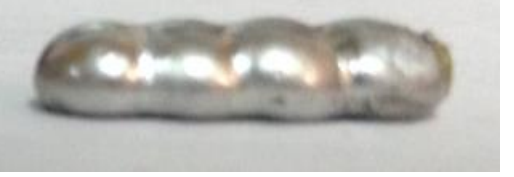

Figure 8. Fusion situation of more than two droplets $(\mathrm{S}<\mathrm{D})$

The figure 8 shows the fusion situation of more than two droplets. We can see that it has the better fusion between metal droplet, and the fusion rate is high. This method can avoid clearance and fusion line in the fusion area, but also inhibit the formation of crack defects in the area, and significantly higher droplet forming morphology. When jet frequency and thermal physical properties of molten droplets to determine, adjusting the nozzle temperature, distance and substrate speed, it can obtain the appropriate droplet distance and temperature of molten droplets, reasonable fusion rate between the droplets, thus eliminating the pores between the droplets. 


\section{Conclusion}

A 3D model for successive deposition of molten Al droplets onto a horizontally moving substrate was developed based on a VOF method. The simulations with this model could agree well with the experimental results and provide an insight into the spreading and fusion of molten Al droplets during successively deposition, and yielded following specific results.

(1) In this DOD jetting, both simulated and experimental results demonstrate that deposited droplets have high-profile shape, which would be useful for the improvement of the efficiency and accuracy of UDJ technology.

(2) Through the successive four droplets spreading and fusing one and another, it can be seen that the eventually spreading height $h$ after solidification of the four droplets is essentially the same. This explains that the forming process is good, providing favorable conditions for forming the next floor.

(3) In metal micro-droplet deposition, the internal defect can be eliminated or suppressed through adjusting process parameters such as the nozzle temperature, nozzle distance and substrate preheating temperature, improving the accuracy of formed parts.

(4) In the process of deposition, the carrying heat of later deposition molten droplets makes partial remelt of the solidified surface, in order to realize the metallurgical combination between each other, which make the whole parts get some of the surface of the forming quality and precision. Therefore, the existences of the fusion line is the primary cause of crack formation and extend continuously, by adjusting the parameters such as nozzle temperature, nozzle distance and substrate temperature and so on can eliminate the metal fusion defect.

\section{Acknowledgements}

This work has been supported by the National natural science Foundation of China (No. 51605379) and the national high technology research and development program (863) project of China (No. 2015AA042503).

\section{References}

[1] F. Gao, A. Sonin, Precise deposition of molten micro-drops: the physics of digital micro-fabrication, Proc. R. Soc. Lond. A 444 (1994) 533-554.

[2] L.J. Zarzalejo, K.S. Schmaltz, C.H. Amon, Molten droplet solidification and substrate remelting in micro-casting Part I: Numerical modeling and experimental verification, Heat Mass Transfer 34 (1999) 477-485.

[3] J.P. Kruth, Material increases manufacturing by rapid prototyping techniques, Ann. CIRP 40 (2) (1991) 603-614.

[4] M. Orme, A novel technique of rapid solidification net form materials synthesis, J. Mater. Eng. Perform. 2 (3) (1993) 399-405.

[5] M. Orme, C. Huang, J. Courte, Deposition strategies for control of microstructures micro porosity and surface roughness in droplet-based solid freeform fabrication of structural materials, in: E.F. Matthys, W.G. Truckner (Eds.), Melt Spinning, Strip Casting and Slab Casting, The Minerals, Metals and Materials Society, Warrendale, PA, 1996, pp. 125-143.

[6] M.E. Orme, C. Huang, J. Courter, Precision droplet-based manufacturing and material synthesis, Atomization Sprays 6 (1996) 305-329.

[7] Liu Q, Orem M. J Eng. Molten droplet solidification and substrate remelting in microcasting .Manufacture [J], 2001, 215(10): 1333

[8] AMON.C.H, SCHMALTZ.K.S, MERZ.R, et.al. Numerical and experimental investigate of interface bonging via substrate remelting of an impinging molten metal droplet [J].Journal of heat transfer, 1996, 118(1):164-172. 
[9] NEAGU.M. Study of remelting process during the droplet-based solid freeform fabrication [J].The annals dungaree de jobs University of Galati, fascicle v: technologies in mechanical engineering, 2004, 5:35-39.

[10] John D. Benrnardin, Clinton J. Stebbins, Issam Mudawar. Mapping of impact and heat transfer regimes of water drops impinging on a polished surface. International Journal of Heat and Mass Transfer. 1997, 40 (2):247-267.

[11] G.E. Cossali, M. Marengo, M. Santini. Thermally induced secondary drop atomisation by single drop impact onto heated surface.International Journal of Heat and Mass Transfer. 29 (2008):167-177.

[12] M. Pasandideh-Fard, S. D. Aziz, S. Chandra, J. Mostaghimi. Cooling effectiveness of a water drop impinging on a hot surface. International Journal of Heat and Fliud Flow. 22 (2001):201-210.

[13] N. Nikolopoulos, A. Theodorakakos, G. Bergeles. A numerical investigation of the evaporation process of a liquid droplet impinging onto a hot substrate.International Journal of Heat and Mass Transfer.50 (2007):303-319.

[14] George Strotos, Manolis Gavaises, Andreas. Numerical investigation on the evaporation of droplets depositing on heated surfaces at low Weber numbers. International Journal of Heat and Mass Transfer.45 (2007):213-216.

[15] Fukai, J., Shiliba, Y., Yanmaoto et al. wetting effects on the spreading of a liquid droplet colliding with a surface: experiment and modeling. Phys. Fluids 1995, 7 (2):236-247.

[16] L.J. Zarzalejo, K.S. Schmaltz, C.H. Amon, Molten droplet solidification and substrate remelting in microcasting Part I: numerical modeling and experi- mental verification. International Journal of Heat and Mass Transfer 34 (6) (1999) 477-485.

[17] S. Haferl, D. Poulikakos, Experimental investigation of the transient impact fluid dynamics and solidification of a molten microdroplet pile-up, Journal of Heat and Mass Transfer 46 (2003) 535-550.

[18] Y.P. Chao, L.H. Qi, et al., Experimental verification and procurement of slice profile data of STL model in metal droplet deposition manufacturing, China Mechanical Engineering 20 (22) (2009). 207-215.

[19] M. Fang, S. Chandra, C.B. Park, Experiments on remelting and solidiciation of molten metal droplets deposited in vertical columns, Journal of Manufactur- ing Science and Engineering 129 (2007) 311-318.

[20] C. Escure, M. Vardelle, Experimental and Theoretical Study of the Impact of Alumina Droplets on Cold and Hot Substrates, Plasma Chemistry and Plasma Processing 23 (2) (2003) 185-221.

[21] J. Luo, L.H. Qi, et al., Research on lateral instability of the uniform charged droplet stream during droplet based freeform fabrication, International Journal of Machine Tools and Manufacture 48 (2008) 289-294.

[22] M. Fang, S. Chandra, C.B. Park, Heat transfer during deposition of molten aluminum alloy droplets to build vertical columns, Journal of Heat Transfer 131 (112101) (2009) 1-7.

[23] X.S. Jiang, L.H. Qi, J. Luo, H. Huang, J.M. Zhou, Research on accurate droplet generation for micro-droplet deposition manufacture, International Journal of Advanced Manufacturing Technology 49 (2010) 535-554.

[24] V. Butty, D. Poulikakos, J. Giannakouros, Int. J. Heat Fluid Flow 23 (2002) 232-241.

[25] S. Kamnis, S. Gu, T.J. Lu, C. Chen, J. Phys. D: Appl. Phys. 41 (2008) 165303.

[26] R. Ghafouri-Azar, S. Shakeri, S. Chandra, J. Mostaghimi, Int. J. Heat Mass Transfer 46 (2003) 1395-1407.

[27] Q. Xu, V.V. Gupta, E.J. Lavernia, Acta Mater. 48 (2000) 835-849. 